\title{
Assessing the Pattern of Utilisation and Out of Pocket Expenditure in Public and Private Hospitals in India - Lessons for Universal Health Coverage from the Healthcare Rounds of National Sample Survey 1996 to 2017
}

Samir Garg ( $\sim$ koriya@gmail.com )

State Health Resource Centre, Chhattisgarh, India https://orcid.org/0000-0003-4915-0731

Kirtti Kumar Bebarta

State Health Resource Centre, Chhattisgarh, India

Narayan Tripathi

State Health Resource Centre, Chhattisgarh, India

\section{Research article}

Keywords: Out of Pocket Expenditure (OOPE), Catastrophic Health Expenditure (CHE), healthcare, Medium Income Countries (LMICs)

Posted Date: December 1st, 2020

DOI: https://doi.org/10.21203/rs.3.rs-115173/v1

License: @ (i) This work is licensed under a Creative Commons Attribution 4.0 International License. Read Full License 


\section{Abstract}

Introduction: Out of Pocket Expenditure (OOPE) contributes to impoverishment and Catastrophic Health Expenditure (CHE) and restricts equitable access to healthcare in many Low and Medium Income Countries (LMICs), including India. Indian government has implemented different strategies to expand access and to reduce OOPE in public and private hospitals in its mixed healthcare system. The study aims to assess the long-term pattern of utilization, OOPE and $\mathrm{CHE}$ in public and private hospitals and to draw policy lessons for Universal Health Coverage in India.

Methods: Indian government conducts periodic household surveys called National Sample Survey (NSS). Unit data from the last four rounds of NSS (1996 to 2017) on healthcare utilization were analysed. Multivariate analysis was used to find out determinants of utilization, choice of provider, OOPE and CHE. Propensity Score Matching was applied to find effect of specific variables on OOPE and CHE.

Results: The share of public-sector in hospital-utilisation fell from 1996 to 2004 but grew consistently after 2004, reaching 51\% of utilization in 2017. Socioeconomically vulnerable sections were more likely to utilize public-sector. Mean OOPE per hospitalization in public-sector registered a decline from 2004 to 2017, while it increased substantially in private-sector. OOPE in private sector was around six times greater than public sector in 2017 and incidence of CHE was nine times. Utilising private-sector was an important determinant of incurring CHE. Coverage under publicly funded insurance was ineffective in reducing OOPE or CHE.

Discussion: Public sector provided effective protection to the poor from financial risk. While, the structural-adjustment policies of 1990 s had resulted in reduction in public-sector utilisation, the supply-side strengthening of public sector after 2005 was more effective in improving access and financial-protection. For achieving UHC, Indian health-system needs increased public funding for strengthening public-sector, especially to provide services for NCDs and injuries. Persistently high OOPE in private-sector raises doubts whether public-funding or contracting can align provider incentives with goals of UHC. The debate on public-private provider mix and financing policies continues to hold relevance for health-systems performance across LMICs.

\section{Introduction}

Universal Health Coverage (UHC) has been agreed as a key global target for health under the Sustainable Development Goals of United Nations [1]. UHC is aimed at improving access and financial protection for healthcare [2]. Out of Pocket Expenditure (OOPE) is a big contributor to impoverishment globally, pushing more than a 100 million into poverty annually [2]. It is a major cause of catastrophic health expenditure (CHE) for households. High OOPE also causes inequity in access to healthcare $[3,4]$.

The problem of high OOPE on healthcare has been found to be very severe in Low and Medium Income Countries (LMICs) including India [5-8]. OOPE constituted 59\% of total health expenditure in India in 2016-17 [9]. OOPE when assessed relative to income has been found to be regressive in India. India has high levels of $\mathrm{CHE}$ incidence and it is highly concentrated among the poor [5]. Researchers have pointed out the adverse impact of high OOPE on equity in healthcare in India [10-12].

The determinants of OOPE as reported in the existing global research include the per capita income, age structure of population, the disease-pattern or the epidemiological needs of population [6]. Some studies in India have also reported similar findings [12-14]. Existing global research has also pointed out the health systems and policy factors that have a bearing on OOPE. Such factors included the amount of government expenditure on health, overseas financial assistance, relative share of public and private providers in provision of healthcare services, extent of gate-keeping by public providers at primary level, population coverage under insurance schemes, mechanisms being used for paying providers and technologies used in medical practice [6, 15, 16].

According to the National Health Policy of India (2017), the primary objective of the health system is ensuring universal access to healthcare services to the entire population, without any financial burden [17]. India's health system is characterized by the co-existence of public and private health care providers [10]. Over the last two decades, the Indian government has implemented different strategies to expand access and to reduce OOPE in public as well private sectors. India has implemented national and state schemes of PFHI for curtailing OOPE for hospital-care for more than decade now [18].

There have been some studies in India that have examined changes in OOPE due to coverage under PFHI [18-22]. But studies that have examined OOPE with respect to important policy reforms in India other than PFHI have been rare [23]. Existing studies on hospital care have not examined the long-term patterns of OOPE according to the type of providers utilized. Understanding the pattern of healthcare utilization, OOPE and CHE over the last two decades can be useful in informing the future policies on healthcare financing in India. The current study is aimed to assess the pattern and determinants of utilization, OOPE and CHE for hospital care in India and to draw lessons for UHC.

\section{Methods And Materials Dataset:}

The central ministry of statistics of Indian government has a system of conducting nationally representative surveys known as the National Sample Surveys (NSS) [13, 24-30]. NSS includes periodic national household surveys on Health which cover morbidity, healthcare utilisation and 00PE [13]. The first such round took place in 1986. The most recent dataset was collected in 2017 and has become available recently. It was the 75th round and the three rounds prior to this were the 71st, 60th and 52nd round in 2014, 2004 and 1996 respectively [24-30]. The current study analysed the last four rounds of the NSS on Health from 1996 to 2017. The above rounds have been used widely for research on healthcare utilization and OOPE [13, 20, 21, 23, 31, 32]. Researchers have observed that the above rounds provide comprehensive information on morbidity patterns, health care, type of providers (public or private) and out of pocket 
expenditure for hospitalization [23,33]. NSS has reported adequate respondent-cooperation rates in its various Health rounds [24-30, 32]. The four rounds are similar in design, content and coverage, and thereby provide comparable results [22, 23].

\section{Sample:}

NSS rounds on Health have a large sample. Their sample is population based and nationally representative [23]. Four cross-sections were used for the analysis. The number of individuals covered in the four rounds in 1996, 2004, 2014 and 2017 were 639159, 387017,338305 and 555352 respectively [24-30]. NSS followed a two-stage stratified sampling. Detailed information on the sample design is available in NSS documents [24-30]. The sampling weights were taken into account in the analyses as applicable. For a detectable difference of $5 \%$ at $95 \%$ confidence and a design effect of 1.5 , a minimum of 574 hospitalizations were required in each round. The actual number of hospitalizations covered, including child birth and maternal care in the four rounds were $26526,35566,57456$ and 93925 respectively.

\section{Data Analysis:}

All hospitalizations, including those for maternal care were included in the analysis for all the four rounds. Out of Pocket Expenditure (OOPE) was calculated for each episode by adding medical expenses and expenses on transportation and deducting any cash-reimbursements received by the patient. OOPE amounts for 1996, 2004 and 2014 were adjusted at 2017 prices for valid comparison, as done by recent studies [21, 22, 34]. For the above adjustment, price deflators for rural (agricultural labour) and urban areas (industrial workers) were used [21, 22, 34, 35]. The survey collected data on usual monthly consumption expenditure and it was multiplied by twelve to calculate the Usual Annual Consumption Expenditure. Recent studies analyzing the NSS datasets have used the same procedure for calculating Annual Household Consumption Expenditure [20-22].

Financial Protection was measured in terms of Catastrophic Health Expenditure (CHE) as proposed by Wagstaff and Doorslaer [36]. A threshold of 25\% of concerned household's Annual Consumption Expenditure were taken for CHE and named CHE25 [20, 21]. The analysis was repeated for $10 \%$ and $40 \%$ thresholds.

The survey data was analysed using STATA-15. The list of variables in the study is given in Additional File - S1. Cross-tabulations were carried out for descriptive analysis and the indicators were reported with $95 \%$ confidence intervals (Cl). Multivariate analysis was used to find out the determinants of utilization, choice of provider, OOPE and CHE25. Ordinary Least Squares (OLS) regression was applied for OOPE. Logistic model was used for binary outcome variables (Utilisation, CHE25). Significance was taken at $95 \%(p<0.05)$. Propensity Score Matching (PSM) was applied to find out the effect of utilising public sector (as compared to utilisation in private sector) on OOPE and on CHE25.

PSM has been used widely for evaluating PFHI, including in India [20, 22, 37-39]. For finding out the effect of PFHI enrolment on OOPE and CHE25, Average Treatment Effect on the Treated (ATET) under PSM modeling was used. For PSM, the area of common support and bias balance after matching was checked, using STATA-15. Since PFHI in India was focused on covering the poorer sections of population, PSM was repeated for the bottom two quintiles of the dataset [20].

Difference in Difference (DID) is known to be a suitable method for addressing selection issues in insurance (37-39). DID was applied for utilisation in private sector to see whether PFHI made any impact on OOPE in private sector. DID requires a 'treated' and a 'control' group, that are compared before and after an intervention. For this purpose, Andhra Pradesh and Telangana - the two states with highest rate of enrolment under PFHI (67\% population covered in 2017) were taken as 'treated'. Bihar and Jharkhand - two states with nearly zero rate of enrolment under PFHI ( $0.1 \%$ population covered in 2017$)$ were taken as 'control'. Since PFHI was started in India between 2004 and 2017, these years were taken as 'before' and 'after' respectively.

\section{Results}

\section{Sample Profile}

The sample profile for the four rounds of survey is given in Additional File - S2.

\section{Hospital Utilisation}

The proportion of individuals who utilised hospital-care is given in Table 1. It includes the hospitalisations for child-birth and maternal care.

Table 1 Proportion of Individuals Hospitalised (\% with 95\% Cl)

\begin{tabular}{|lllll|}
\hline Round & 1996 & $\mathbf{2 0 0 4}$ & $\mathbf{2 0 1 4}$ & $\mathbf{2 0 1 7}$ \\
Hospitalisation Rate & 1.49 & 2.71 & 4.86 & 4.09 \\
& $(1.45-1.52)$ & $(2.65-2.75)$ & $(4.77-4.94)$ & $(4.03-4.15)$ \\
\hline
\end{tabular}


Multi-variate logistic regression showed that women, married persons, rural inhabitants, persons belonging to smaller households and those enrolled under PFHI were more likely to utilize hospital-care than the other corresponding categories (Additional File - S3). The poorer quintiles, the Scheduled Tribes, informal workers and the illiterate individuals were less likely to utilize hospital care than the other corresponding categories.

\section{Pattern of Out of Pocket Expenditure:}

The mean OOPE per hospitalization is given in Table 2.

Table 2

Mean OOPE in Indian Rupees (INR) for Hospitalisation - Overall and by type of provider (with $95 \% \mathrm{Cl})$

\begin{tabular}{|lllll|}
\hline Type of Provider & $\mathbf{1 9 9 6}$ & $\mathbf{2 0 0 4}$ & $\mathbf{2 0 1 4}$ & $\mathbf{2 0 1 7}$ \\
\hline Public & 9453 & 9045 & 6429 & 4755 \\
& $(8918-9988)$ & $(8599-9492)$ & $(6156-6702)$ & $(4620-4890)$ \\
\hline Private & 20038 & 20841 & 28173 & 28961 \\
& $(18858-21217)$ & $(20102-21580)$ & $(27501-28845)$ & $(28464-29458)$ \\
\hline Overall & 15605 & 16341 & 18303 & 16626 \\
& $(14982-16229)$ & $(15865-16818)$ & $(17912-18694)$ & $(16364-16889)$ \\
\hline
\end{tabular}

Table 2 shows that the mean OOPE for hospitalization in public-sector declined from 1996 to 2017 and the rate of decline was sharper after 2004 . Mean OOPE in private sector increased, especially from 2004 to 2014. OOPE in public sector was lower than that in private sector and the difference between the two grew from 1996 to 2017. The ratio of mean OOPE in private sector to that in public sector was 2.1 in 1996 and 2.3 in 2004 , but it increased to 4.4 in 2014 and became 6.1 in 2017.

OLS regression for finding out determinants of OOPE showed that the size of OOPE was likely to be greater for hospitalizations of men, married persons, informal workers and infants and elderly persons; compared to other corresponding categories (Additional File - S4). OOPE also increased with income and education. Hospitalisations for injuries and NCDs and were likely to involve greater OOPE than other disease-categories. OOPE increased with increase in duration of hospitalization. Among the study variables, the type of provider had the biggest effect on size of OOPE. Those utilising private-sector hospitals were likely to incur significantly greater OOPE than those hospitalized in public facilities.

PSM model for effect of public-sector utilisation on OOPE showed INR 18,197 less OOPE was likely per episode in public hospitals as compared to private hospitals (Table 3 ).

Table 3

\begin{tabular}{|c|c|c|}
\hline \multirow[t]{2}{*}{ Variable } & Effect & \\
\hline & Coeff. & $\mathrm{P}$ \\
\hline OOPE (INR) & -18197 & $<0.001$ \\
\hline CHE25 & -0.199 & $<0.001$ \\
\hline
\end{tabular}

\section{Pattern of CHE:}

The proportion of episodes involving catastrophic health expenditure at $25 \%$ threshold of annual household expenditure (CHE25) is given in Table 4. 
Table 4

Proportion (\%) of hospitalizations resulting in CHE25 - Overall and by type of

provider (with $95 \% \mathrm{Cl}$ )

\begin{tabular}{|lllll|}
\hline Type of Provider & $\mathbf{1 9 9 6}$ & $\mathbf{2 0 0 4}$ & $\mathbf{2 0 1 4}$ & $\mathbf{2 0 1 7}$ \\
Public & 6.1 & 9.9 & 4.6 & 2.7 \\
& $(5.2-7.1)$ & $(9.2-10.7)$ & $(4.1-5.1)$ & $(2.4-3.1)$ \\
Private & 13.8 & 21.4 & 23.5 & 23.6 \\
& $(12.1-15.8)$ & $(20.6-22.4)$ & $(22.5-24.5)$ & $(22.7-24.4)$ \\
Overall & 10.6 & 13.1 & 14.9 & 12.9 \\
& $(9.5-11.7)$ & $(12.6-13.7)$ & $(14.3-15.5)$ & $(12.5-13.4)$ \\
\hline
\end{tabular}

Table 4 shows that the CHE25 for hospitalization increased sharply from 1996 to 2004 . CHE25 for hospitalization in public-sector also increased from 1996 to 2004 but declined sharply thereafter. CHE25 in private sector increased over the years. The occurrence of CHE25 was twice as common for private sector utilisation as compared to using public sector in 1996. The difference grew over the years. In 2017, CHE25 was almost nine times as common for private sector utilisation in comparison to public sector.

Logistic regression for finding out determinants of CHE25 showed that its occurrence was more likely for hospitalizations of men, persons from bigger households, married persons, rural inhabitants, informal workers and the elderly (Additional File - S5). CHE25 also increased with education. The Scheduled Tribes were less likely to incur CHE in comparison to other social groups. Higher levels of poverty were associated with increased chances of CHE25. Hospitalisations for injuries and NCDs and were likely to involve greater incidence CHE25 than the communicable diseases. CHE25 increased with length of hospitalization. Those utilising private-sector hospitals were likely to have significantly greater incidence of CHE25 than those hospitalized in public facilities.

PSM model showed that utilisation in public hospitals was likely to have significantly less incidence of CHE25 than in private hospitals (Table 3 ).

\section{Effect of Publicly Funded Health Insurance (PFHI) on OOPE and CHE:}

The 2014 round was the first NSS round conducted after the PFHI schemes got introduced in India. Table 5 gives the mean OOPE per episode according to PFHI-enrolment status of individuals utilising hospital care.

Table 5

Mean OOPE (in INR) by Insurance Enrolment Status, with 95\% $\mathrm{Cl}$

\begin{tabular}{|llllll|}
\hline \multirow{2}{*}{ PFHI enrolled } & Public & - & $\mathbf{2 0 0 4}$ & $\mathbf{2 0 1 4}$ & $\mathbf{2 0 1 7}$ \\
& & & - & 4452 & 4350 \\
& & & & $(4079-4826)$ & $(22197-24068)$ \\
\cline { 2 - 6 } & Private & - & - & 22268 & 23132 \\
\multirow{2}{*}{ Not Enrolled } & Public & 9453 & 9045 & $(21317-23218)$ & $(22197-24068)$ \\
& & $(8918-9988)$ & $(8599-9492)$ & $(5876-6396)$ & $(4358-4645)$ \\
& & & 20841 & 27265 & 28821 \\
& \multirow{2}{*}{ Private } & 20038 & $(20102-21580)$ & $(26572-27958)$ & $(28282-29360)$ \\
\hline
\end{tabular}

Table 5 shows that the mean OOPE was marginally lower for those enrolled under PFHI. Public sector was several times cheaper than private sector for the PFHI-enrolled as well as the non-enrolled.

PSM model for effect of PFHI on OOPE showed that insurance was likely to have a small effect on OOPE (Table 6). When the PSM was repeated for the bottom two quintiles, there was no significant effect of PFHI on OOPE (Table 6). 
Table 6

PSM (ATET) for Effect of PFHI on OOPE and CHE25

\begin{tabular}{|llcll|}
\hline Variable & \multicolumn{3}{l|}{ Complete Dataset (all quintiles) } & \multicolumn{2}{l|}{ Bottom two quintiles dataset } \\
& Coeff. & $P$ & Coeff. & $P$ \\
\hline OOPE & $-2853^{*}$ & $<0.001$ & 227 & 0.67 \\
\hline CHE25 & $-0.02^{*}$ & $<0.001$ & -0.01 & 0.18 \\
\hline${ }^{*}<0.05$ & & & & \\
\hline
\end{tabular}

Table 7 gives the CHE25 occurrence for hospitalizations according to insurance-enrolment status of patients.

Table 7

Proportion of episodes (\%) involving CHE25 by Insurance Enrolment

\begin{tabular}{|lllll|}
\hline & $\mathbf{1 9 9 6}$ & $\mathbf{2 0 0 4}$ & $\mathbf{2 0 1 4}$ & $\mathbf{2 0 1 7}$ \\
\hline PFHI Enrolled & - & - & 14.1 & 13.7 \\
& & & $(12.5-15.7)$ & $(12.5-14.9)$ \\
\multirow{2}{*}{ Not Enrolled } & 7.6 & 13.1 & 15.9 & 13.2 \\
& $(6.8-8.4)$ & $(12.6-13.7)$ & $(15.2-16.6)$ & $(12.7-13.7)$ \\
\hline
\end{tabular}

Table 7 shows that CHE25 was nearly equal for the PFHI-enrolled and the non-enrolled.

PSM for effect of PFHI on CHE25 showed that the PFHI-enrolled had 2 percentage points less likelihood of CHE25 for hospitalization than the non-enrolled. When the PSM was repeated for the bottom two quintiles, there was no significant effect of PFHI on CHE25.

DID for highest enrolment states (Andhra Pradesh-Telangana) and zero-enrolment states (Bihar-Jharkhand) for 2004 and 2017 showed that PFHI-enrolment had no significant effect on OOPE or CHE25 for utilizing private hospitals (Additional File S6).

The above analyses were repeated for $\mathrm{CHE}$ at $10 \%$ and $40 \%$ thresholds but the results remained similar.

\section{Pattern for Choice of Provider:}

The share of public providers in utilisation of hospital care is given in Table 8 .

Table 8

\begin{tabular}{|c|c|c|c|c|}
\hline Round & 1996 & 2004 & 2014 & 2017 \\
\hline \multirow[t]{2}{*}{ Share of Public Providers } & 44.5 & 40.8 & 45.3 & 51.0 \\
\hline & $(43.4-45.7)$ & (39.9-41.7) & $(44.5-46.2)$ & $(50.3-51.6)$ \\
\hline
\end{tabular}

Table 8 shows that the share of public sector fell from 1996 to 2004 . After 2004 it grew in each round and it reached $51 \%$ in 2017. 
Table 9

Share of Public sector in Hospital Utilisation by Different Socio-economic Categories (with $95 \%$ Cl)

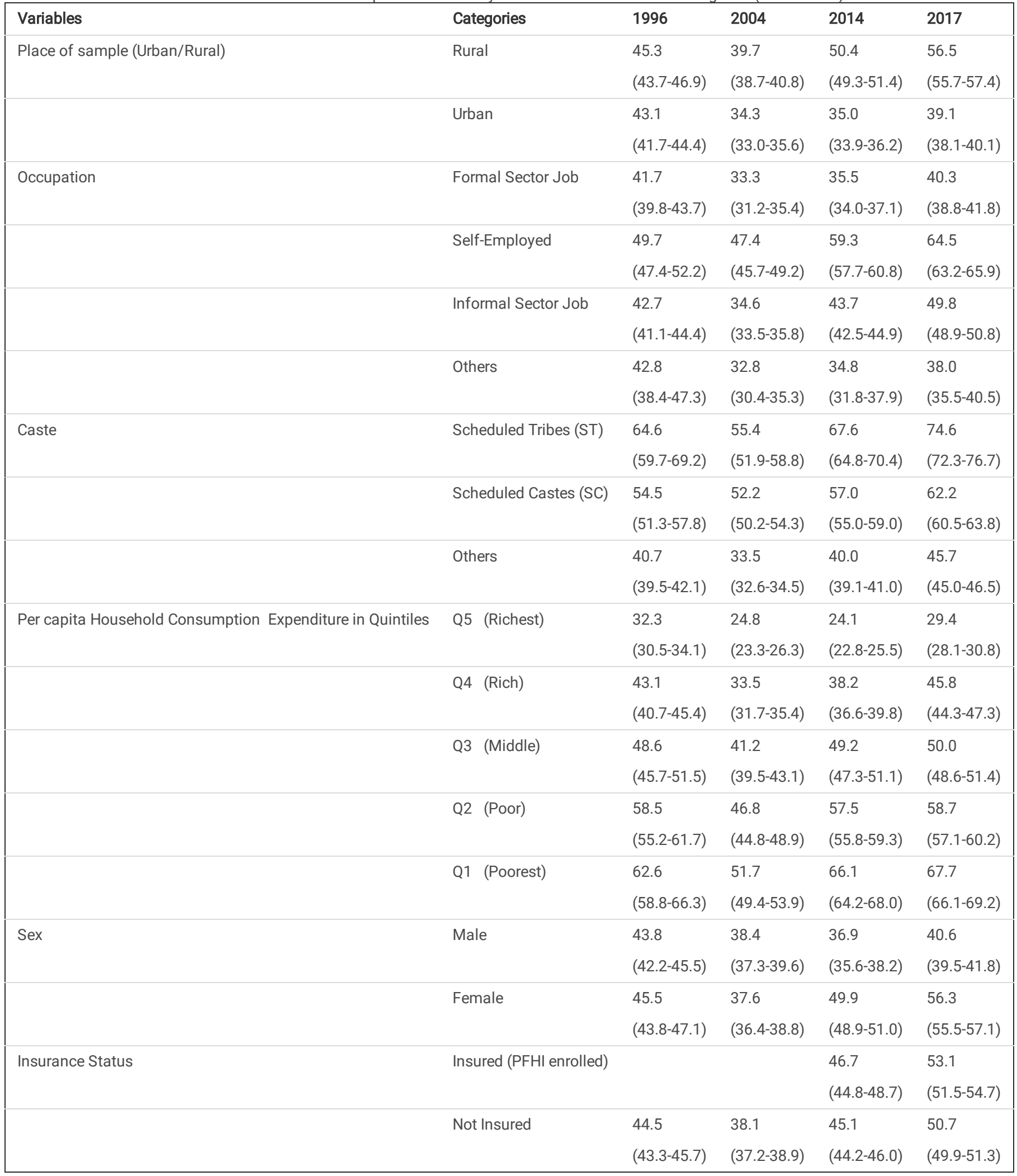

Table 9 shows that the share of public sector in utilisation by most of the categories of population registered a decline from 1996 to 2004 . From 2004 to 2017 , there was a rise in share of public sector in utilisation by most categories and it was more pronounced for the women, rural population, informally employed, the marginalized social groups (ST, SC) and the poorest (bottom two quintiles). The increase in share of public sector utilization was less impressive in case of socio-economically better-off categories. 
Table 10

\begin{tabular}{|c|c|c|c|c|}
\hline Disease Category & 1996 & 2004 & 2014 & 2017 \\
\hline \multirow[t]{2}{*}{ Communicable Diseases } & 47.5 & 39.2 & 40.4 & 45.4 \\
\hline & $(45.1-50.0)$ & $(37.9-40.5)$ & $(38.8-42.1)$ & $(43.9-46.8)$ \\
\hline \multirow[t]{2}{*}{ Non-Communicable Diseases } & 43.8 & 38.7 & 35.5 & 39.6 \\
\hline & $(41.9-45.8)$ & $(36.9-40.5)$ & $(34.1-36.9)$ & $(38.4-40.8)$ \\
\hline \multirow[t]{2}{*}{ Maternal and Reproductive Conditions } & 43.6 & 46.1 & 60.6 & 66.9 \\
\hline & $(38.5-49.0)$ & $(43.7-48.5)$ & $(59.3-61.9)$ & $(65.9-67.9)$ \\
\hline \multirow[t]{2}{*}{ Injuries } & 52.3 & 42.2 & 43.2 & 40.4 \\
\hline & $(48.3-56.2)$ & $(39.3-45.2)$ & $(40.1-46.4)$ & $(38.2-42.6)$ \\
\hline \multirow[t]{2}{*}{ Others } & 40.5 & 37.1 & 33.7 & 36.4 \\
\hline & $(38.3-42.8)$ & $(35.1-39.1)$ & $(29.8-37.7)$ & $(32.2-40.7)$ \\
\hline \multirow[t]{2}{*}{ Overall } & 44.5 & 40.8 & 45.3 & 51.0 \\
\hline & $(43.4-45.7)$ & $(39.9-41.7)$ & $(44.5-46.2)$ & $(50.3-51.6)$ \\
\hline
\end{tabular}

Table 10 shows that, the share of public sector in hospitalizations for all disease-categories other than the maternal conditions registered a decline from 1996 to 2004 . From 2004 to 2017, the share of public sector increased for all categories except injuries. The increase was steepest for maternal conditions, followed by communicable diseases. Use of public hospitals for NCDs showed an increase in more recent years i.e. from 2014 to 2017.

The multivariate logistic regression showed that among the hospitalized, utilisation of public-sector care was more likely for persons belonging to smaller households, men, unmarried persons and those enrolled under PFHI (Additional File - S7). The socio-economically disadvantaged sections of the poor, the Scheduled Tribes and Scheduled Castes and informal workers were significantly more likely to utilize the public sector. Maternal conditions were strongly associated with use of public sector. The utilization of public sector decreased with education status.

\section{Discussion}

The current study found that many vulnerable sections of the population - the poor, the Scheduled Tribes and informal workers were less likely to utilize hospital care. This shows that considerable inequity has persisted in India in terms of access to hospital care in India. This issue has been highlighted by many studies from India as well as from other LMICs [10, 40-45].

Similar to the findings reported in earlier studies, hospitalisations for injuries and NCDs and were likely to involve greater OOPE and CHE than other diseasecategories in the current study $[13,33,34,46]$. Studies in other parts of the world have also found that OOPE increased with NCDs [47-51].

Hospitalizations of informal workers were found to involve greater OOPE and CHE in the current study. Rural population was more vulnerable to CHE. Though the poorer sections incurred less OOPE than the rich, yet their chances of incurring CHE were found to be greater. These findings show inequity in facing financial risk for hospital-care. Earlier studies have also reported similar concerns in terms of the rural population facing greater OOPE [52]. Studies have also pointed out the poor facing greater likelihood of $\mathrm{CHE}[10,13,20,33,43,53]$. The poorer states and districts of the country are affected worse by the burden of health spending $[33,54,55,56]$. The burden of OOPE has increased over time and the rate of increase was found to be sharper for the lower income quintiles [53].

A key finding of the current study was that utilization in private-sector hospitals involved significantly greater OOPE and incidence of CHE than public hospitals. In 2017, OOPE in private sector was six times greater than in public sector. Some studies in India have reported similar findings [10, 13, 20, 32, 43, 57]. According to the current study, the public sector provided protection to the poor from catastrophic expenditure. Incidence of $\mathrm{CHE} 25$ in 2017 was nine times greater in private sector than in public sector. Studies in India and several LMICs have reported that OOPE was greater for private sector utilization, including for in-patient care $[13,20,32,49,58-63]$.

The increase in cost in private sector in India has been attributed to overcharging and unnecessary procedures [53, 64-75]. There has been little regulation of private sector in India in terms of quality or costs [64]. Many of the problems private sector in India have been echoed for many other LMICs [59]. Possibility of provider induced demand has been pointed out as a key problem with for-profit providers and an important cause of high 00PE [76-79]. Some have indicated that public funded and privately provided care suffers from provider capture [80].

Some global policy actors have advocated for a greater role of private sector in healthcare [81-86]. Many have acknowledged the likelihood of market failure in healthcare but have advocated for greater involvement of private-sector by finding methods to mitigate the market-failure [87-90]. Others have warned that health systems relying predominantly on private-sector are unlikely to achieve meaningful progress towards equity and UHC [91-98]. Proponents of greater role of private-sector feel that its capacity needs to be used to expand access and improve quality [99]. But others have expressed concerns regarding its expansion considering its poor affordability and tendencies to over-provide [99]. Lack of adequate evidence for or against the private-sector and its 
involvement in public services has been one of the common themes in existing literature [100-103]. Studies have suggested that engaging private-sector can be useful for some specific and restricted needs but was unlikely to work for a system wide scale for purposes of UHC [102, 104].

In terms of the determinants of choice of provider, the current study found that the socio-economically disadvantaged sections of - the poor, the Scheduled Tribes and Scheduled Castes and informal workers were significantly more likely to utilize the public hospitals. Earlier studies have also pointed out a similar pattern [20,32, 40, 41, 43]. A similar reliance of the poor on the public sector has been reported from many LMICs [49].

The current study found that incidence of CHE increased in public sector from year 1996 to 2004 and the share of public sector in hospital-care declined in the period. There is evidence that the above decline in public sector had started before 1996. Studies comparing the first Health round of NSS (1986) with the 1996 round found that the share of public sector in hospitalizations declined sharply. The period around 1990 was when the Structural Adjustment Programme (SAP) was implemented in India at the advice of international financial institutions $[105,106]$. This was part of widespread changes happening globally, including in the developing world. The key components of the reforms in India under the SAP were - fiscal discipline and downsizing public sector, introducing user fees for public services and promoting expansion of private sector healthcare $[107,108]$. World Bank played a key role in advancing SAP reforms in health sector in India. Citing the deficiencies in public sector, it advocated privatization of healthcare. It was advocated that patients were likely to get better services if they paid for them. The ability of the people to pay was also expected to rise with fast growth of economy. The episode based healthcare was seen as a private good and efficiency was expected to be achieved through competition and the choice exercised by patients as paying consumers [108$110]$.

Public expenditure on healthcare in India was stagnant in the 1996-2004 period at less than 1\% of Gross Domestic Product (GDP) [111, 112]. Although Indian economy grew at a rapid pace during the 1990s, it did not translate into an increase in public funding for healthcare [106]. From 1995 to 2006, public expenditure on health remained stagnant both at the national and state levels in India [113]. The above period was characterized by chronic under-funding of public sector [106]. The reforms included reducing investment in public hospitals, especially at tertiary level [108]. The lack in health service provision resulted in inaccessibility of health services for the general population [42]. The inability of the public sector to meet the healthcare needs resulted in dependency on private providers. The private out-of-pocket expenditure was on the rise [109]. While the Indian GDP grew at a brisk pace, there was still very significant impoverishment due to CHE [114].

User fees were imposed on utilisation of public sector in India, starting from $1992[106,107,115]$. Cost recovery in public sector was a key component of World Bank's advice for LMICs [106, 108]. Studies in India and globally have reported the adverse effects of user fees on access and expenditure of the poor for healthcare [11, 42,112, 116-118]. User fees could have contributed to the reduction in access to public sector in India. The pharmaceutical sector was liberalized in India in 1990s and the price controls were reduced considerably [109]. The rise in medicine costs has also been cited as a key contributor to rising OOPE in India, including in the public sector [106, 115].

The current study found that hospital utilisation grew in the period 1996 to 2004 and so did the share of private sector in hospital-care. Other studies have also reported similar findings $[42,112,115]$. In order to meet the increasing demand including from an expanding middle-class, Indian governments promoted private hospitals by giving them free land and other subsidies [42, 107, 109, 112]. Encouragement was offered by government for increasing private investment in hospitals, including through foreign capital. The number of private hospitals rose sharply in the period [109]. The shortage of services in public sector further boosted the growth of private sector [112, 115]. The reforms agenda of the period was focused on increasing the role of private sector [40, 42].

In terms of equity, the access of the poor to hospital care registered a decline and OOPE increased substantially from 1990s to 2004 [42, 106, 112]. Private hospitals were always accessed less by the poorer sections due to affordability barrier. But in the above period, even public sector was utilized more by the rich [112]. Researchers have concluded that SAP policies pursued in India from 1990s to 2004 had a bad effect on the public sector and resulted in rise in CHE, impoverishment and inequity $[40,42,74,112,115]$.

The current study shows that many of the above patterns got reversed after 2004. The share of public sector in hospital utilization grew substantially from 2004 to 2017. In the above period, the share of public sector in out-patient care also increased [32]. The OOPE per episode of hospitalization in public sector declined from 2004 to 2017, while the OOPE for utilizing private hospitals increased in this period. The period after 2004 has seen two major policy reforms in Indian healthcare - a) Launch of National Rural Health Mission (NRHM) in 2005 b) Publically Funded Health Insurance (PFHI) schemes [74].

In response to the high proportion of OOPE and to make private-sector affordable for the poor, PFHI schemes got introduced in many parts of the world including India $[37,67,119,120]$. While a national insurance scheme began in India in 2008 , some states had started such schemes a few years earlier. These PFHI schemes were focused almost exclusively on in-patient or hospital-care for the poorer sections. The current study found that the schemes were not effective in avoiding CHE for the insured. Increase in insurance cover did not reduce financial risk in India [20, 21, 33]. There was negligible decrease in 0OPE for utilization in private sector because of such schemes.

The ineffectiveness of the insurance-cover through PFHI in Indian situation has been attributed to "double-billing" i.e. private providers tend to appropriate the insurance-benefit while taking extra charges from the patients illegally [21, 22, 70-71]. The continued poor regulation of private sector contributed to failure of PFHI programmes $[69,73.121,122]$. Another assessment is that the development of PFHI in India was market oriented and it had a damaging effect on access and equity $[106,123]$. The problems seem to have persisted in the revised national PFHI scheme called Ayushman-Bharat Pradhan Mantri Jan Arogaya Yojana (AB-PMJAY) [22]. PFHls have been promoted globally as a vehicle for UHC [38, 124]. The evidence on effectiveness of PFHIs in ensuring financial protection in LMICs has not been very convincing so far [37-39, 125-133].

There has been a perception that most of the healthcare in India takes place in private sector [134]. Recent policy documents of central government have also stated that private sector accounts for around $80 \%$ of the healthcare in India [135]. Various studies have reported that the share of public-sector in hospital-

Page 9/17 
care in India has been declining [49, 134-135]. Contrary to the above, the current study found that share of public sector in hospital-utilisation in India was rising from 2004 to 2017. In 2017, public sector crossed 50\% share in hospital-care utilisation. The current study included hospitalizations for child-birth in the utilization figures whereas most of the other studies did not. Maternal care has been an area in which the expansion of public sector services was most impressive [23]. This may explain how some of the earlier studies have ended up with a different conclusion regarding the share of public sector in hospital care in India. The dominance of public sector in hospital care has been a phenomenon common to a majority of countries globally [49].

The current study showed that the mean OOPE in real terms and the incidence of CHE for utilizing private sector increased substantially in India from 2004 to 2017. In this period, OOPE and CHE for hospitalisation in public sector decreased. Indian government had introduced NRHM in 2005. It has been called a watershed in health-sector reforms in India [136]. It was initiated to improve the availability of healthcare in rural areas, primarily by increasing funding for existing public sector [55]. It improved government spending on healthcare, both by the central government and the states [136]. Under NRHM, the funding was mainly for supply side strengthening of public sector. More human resources were added to the public sector. One key area of improvement in public services under NRHM was of maternal health [23]. It seems that the maternal care acted as the engine for revival of public hospitals in India. NRHM abolished user fees in maternal, neonatal and child care. In 2012, National Urban Health Mission (NUHM) was introduced to strengthen primary care for the urban poor through supply-side strengthening of public sector. Recently, an emphasis has emerged on services for NCDs including through additional funding by the states $[32,138]$.

States that have improved availability of free medicines and diagnostics in public facilities have achieved remarkable reductions in catastrophic expenditure for the poor $[137,139,140]$. Many feel that as the public sector services expand, there will be fewer takers for private sector [32, 109]. As found in the current study, the argument that the people do not prefer public hospitals does not seem to be true in Indian context.

However, the progress in supply-side reforms has been uneven across states in India $[33,140]$. Further supply-side reforms may be necessary in many states including - attracting and retaining more doctors and health human-resources, strengthening diagnostic services, removing all user fees especially for tests and providing free drugs in public hospitals. Improving quality of care in public facilities can help them in retaining and expanding their clientele.

The debate on health sector reforms needed in India has reached an important juncture now. Researchers have highlighted that there was a lack of consensus regarding the role of private sector in India and the optimal public-private mix [134]. In early 2000s, India had both the options - a) relying on public sector or b) shifting to public funded but largely privately provided services [141]. India has experience of around fifteen years of trying both the options simultaneously for hospital-care. PFHI schemes seem to have largely failed, mainly due to their reliance on private providers in absence of effective regulation. The qualified private providers tend to be concentrated in urban areas $[109,142]$. Supply side strengthening of public sector seems to have given better results for UHC in terms of covering the poor and saving them from catastrophic expenditure. The public sector seems to be more cost-effective than private provisioning [106]. Public spending was also found to be effective in improving the health status of the poor [143]. Public spending on health is still very low but with a growing economy India has the fiscal space to increase it $[8,143,144]$. The recent inclusion of NCDs in essential primary care by Government of India seems to be a step in the right direction [145]. The current study suggests that greater attention is needed in India to also expand the hospital-based services for NCDs and injuries in the public sector.

Global literature has indicated that health systems with greater utilization of public sector were likely to have lower levels of OOPE [146, 147]. Some studies from LMICs have shown that only those utilizing public facilities could avoid OOPE [148]. Some South East Asian LMICs like Srilanka, Malaysia and Thailand achieved remarkably low levels of CHE by relying mainly on public-sector based healthcare delivery and this form of financing has been found to be pro-poor $[92,149-151]$. Recently, it has been suggested that keeping the provider incentives in mind, public spending through public agencies may be more effective in reducing CHE globally [5].

Researchers have suggested that there can be different kinds of trajectories to achieve UHC and design of financing and provisioning policies can have important implications for what the health-systems are able to achieve [152]. The debate on public-private sector roles has relevance for a suitable path for health systems in LMICs. Further research is needed in LMIC contexts on effectiveness of policies for UHC, where provisioning is predominantly through forprofit private sector. Further research is recommended to suggest effective ways for regulation of private sector in India and other LMICs.

Limitations: The first round of NSS on Healthcare (1986) was not included in the analysis though it was relevant to the objectives of the study. The 1986 round did not cover questions on hospital care for maternal conditions [42]. Therefore its results were not comparable with subsequent NSS Rounds.

The NSS dataset does not distinguish between older insurance schemes of Central Government Health Services (CGHS) and Employee State Insurance (ESI) for the formally employed and the current wave of PFHIs that were the focus of this study. Other studies have reported that CGHS and ESIS form a very small proportion of PFHI enrollment and do not affect the results materially [20, 21].

The current study used DID to confirm the effect of PFHI on OOPE and CHE, but defining the 'treated' group involved an approximation.

Quality of care is an important dimension for UHC but it was beyond the scope of current study to include it.

\section{Conclusions}

We conclude that OOPE in private sector in India is many times greater than in public sector, irrespective of enrolment under publicly funded health insurance. Government's insurance schemes have failed to make the private sector affordable to the poor. It is doubtful whether any effective ways exist in Indian context to align the provider incentives with goals of UHC, including through public-funding and contracting of private providers. Public sector utilization has grown in India after 2004 and it provided effective protection to the poor from financial risk. 
While the structural adjustment policies of 1990s caused damage to public sector and reduced its utilisation, the supply-side strengthening of public sector under the National Health Mission has been more successful in improving access and financial protection in India. India certainly needs an increase in public funding for healthcare for moving towards $\mathrm{UHC}$ and it is likely to be more effective if policies focus on further strengthening of public sector, especially to expand services for NCDs and injuries.

Policies of publicly funded and privately provided care need to be evaluated in light of current evidence from LMICs. Out of pocket expenditure is a very important aspect in performance of health-systems and it depends upon national policies. The debate on public-private provider mix and its relationship with financing policies has great relevance for health systems design across LMICs.

\section{Abbreviations}

CHE: Catastrophic health expenditure; CHE10: Catastrophic Health Expenditure computed using the threshold of 10\% of usual annual consumption expenditure; CHE25: Catastrophic Health Expenditure computed using the threshold of 25\% of usual annual consumption expenditure; CHE40: Catastrophic Health Expenditure computed using the threshold of $40 \%$ of usual annual consumption expenditure; Cl: Confidence Interval; DID: Difference in Difference; INR: Indian Rupee; LMIC: Low and Medium Income Countries NSS: National sample survey; OLS: Ordinary Least Squares OOPE: Out-of-pocket expenditure; PFHI: Public Funded Health Insurance; PMJAY: Pradhan Mantri Jan Arogaya Yojana; PSM: Propensity Score Matching RSBY: Rashtriya Swasthya Bima Yojana; UHC: Universal Health Coverage;

\section{Declarations}

\section{Acknowledgements}

Not Applicable.

\section{Funding}

No funding was obtained for this study.

\section{Consent for Publication}

Not Applicable.

\section{Availability of data and materials}

The secondary dataset used are available in public repository of Ministry of Statistics at [microdata.gov.in/nada43/index.php/catalog/81], [microdata.gov.in/nada43/index.php/catalog/105], [microdata.gov.in/nada43/index.php/catalog/135] and [http://www.mospi.gov.in/unit-level-data-reportnss-75th-round-july-2017-june-2018-schedule-250social-consumption-health] for 1996, 2004, 2014 and 2017 rounds of NSS respectively.

\section{Authors' contributions}

SG contributed to the study design and writing of the manuscript. SG, KB and NT analysed the data. All authors read and approved the final manuscript.

\section{Authors' information}

SG works with State Health Resource Centre, Chhattisgarh, India

KB works with State Health Resource Centre, Chhattisgarh, India

NT works with State Health Resource Centre, Chhattisgarh, India

\section{Ethics approval and consent to participate}

The secondary dataset analysed for this article are from the National Sample Survey, $52^{\text {nd }}, 60^{\text {th }} 71^{\text {st }}$ and $75^{\text {th }}$ Rounds, which contain anonymised data in the public domain. The researchers had no access to personal identifiable data. The survey is undertaken by the National Sample Survey Office (NSSO) of the Ministry of Statistics and Programme Implementation of the Government of India. Data available in public domain are approved for use for research purpose by Ministry of Statistics and Programme Implementation, Government of India.

\section{Competing interests}

The authors declare that there are no competing interests. 


\section{References}

1. United Nations (UN). Resolution A/RES/70/1. Transforming our world: the 2030 agenda for sustainable development. In: Seventieth United Nations general assembly, New York, 25 September 2015. New York: United Nations; 2015.

2. World Health Organization. Health systems financing: The path to universal coverage. In: World Health Report 2010. Geneva: WHO; 2010.

3. Xu K, Evans DB, Carrin G, Aguilar-Rivera AM, Musgrove P, Evans T. Protecting households from catastrophic health spending. Health Aff. 2007;26(4):97283.

4. Xie X, Wu Q, Hao Y, Yin H, Fu W, Ning N, et al. Identifying determinants of socioeconomic inequality in health service utilization among patients with chronic non-communicable diseases in China. PLoS One. 2014;9(6):e100231.

5. Wagstaff A, Flores G, Hsu J, Smitz M, Chepynoga K, Buisman LR, et al. Progress on catastrophic health spending in 133 countries: a retrospective observational study. Lancet Glob Health. 2018;6:e169-79.

6. Xu K, Saksena P, Holly A. The determinants of health expenditure: a country level panel data analysis. Working Paper. 2011. Results for Development Institute. Washington DC.

7. van Doorslaer E, O'Donnell O, Rannan-Eliya RP, Somanathan A, Adhikari SR, Garg CC, et al. Effect of payments for health care on poverty estimates in 11 countries in Asia: an analysis of household survey data. Lancet. 2006;368(9544):1357-64.

8. Marten R, McIntyre D, Travassos C, Shishkin s, Longde W, Reddy S, et al. An assessment of progress towards universal health coverage in Brazil, Russia, India, China, and South Africa (BRICS). Lancet. 2014;384:2164-71.

9. National Health Systems Resource Cenrtre. National Health Accounts Estimates for India FY 2016-17. October 2019. National Health Accounts Technical Secretariat (NHATS), National Health Systems Resource Centre (NHSRC), Ministry of Health and Family Welfare (MoHFW). Government of India. New Delhi. Available at: http://nhsrcindia.org/sites/default/files/FINAL\%20National\%20Health\%20Accounts\%202016-17\%20Nov\%202019-for\%20Web.pdf. Accessed on 15th June, 2020.

10. Balarajan Y, Selvaraj S, Subramanian SV. India. Towards universal health coverage 4 health care and equity in India. Lancet. 2011;377(9764):505-15.

11. Gupta I, Chowdhury S, Patra N. Essential Health Package for India: Approach and Costing. Report Submitted to the XIVth Finance Commission. September 2014. Institute of Economic Growth. Delhi.

12. Pandey A, Clarke L, Dandona L, Ploubidis GB. Inequity in out-of-pocket payments for hospitalisation in India: Evidence from the National Sample Surveys, 1995-2014. Soc Sci Med. 2018;201:136-47.

13. Pandey A, Ploubidis GB, Clarke L, Dandona L. Trends in catastrophic health expenditure in India: 1993 to 2014. Bull World Health Organ. 2018;96:18-28.

14. Mohanty SK, Ladusingh L, Kastor A, Chauhan RK, Bloom DE. Pattern, growth and determinant of household health spending in India, 1993-2012. J Public Health. January 2016. 24, pages215-229(2016). DOI 10.1007/s10389-016-0712-0.

15. Raeissi P, Rajabi MR, Mousavi A, Vahedi S, Khalilabad TH. Investigating the Determinants of Healthcare Expenditures in Different Healthcare Systems. Shiraz E-Med J. 2019 September;20(9):e86506.

16. Younsi M, Chakroun M, Nafla A. Robust analysis of the determinants of healthcare expenditure growth: evidence from panel data for low-, middle- and high-income countries. Int J Health Plann Mgmt. 2016. DOI:10.1002/hpm.

17. Government of India. 2017. National Health Policy 2017. Ministry of Health and Family Welfare, Government of India. Available at: http://www.mohfw.nic.in/sites/default/files/9147562941489753121.pdf. Accessed on: 16th June, 2020.

18. Prinja S, Chauhan A, Karan A, Kaur G, Kumar R. Impact of Publicly Financed Health Insurance Schemes on Healthcare Utilization and Financial Risk Protection in India: A Systematic Review. PLoS One. 2017;12(2):e0170996.

19. Karan A, Yip W, Mahal A. Extending health insurance to the poor in India: an impact evaluation of RashtriyaSwasthyaBimaYojana on out of pocket spending for healthcare. Soc Sci Med. 2017;181:83-92.

20. Ranjan A, Dixit P, Mukhopadhyay I, Sundararaman T. Effectiveness of government strategies for financial protection against costs of hospitalization Care in India. BMC Public Health. 2018;18(1):501.

21. Garg S, Chowdhury S, Sundararaman T. Utilisation and financial protection for hospital care under publicly funded health insurance in three states in Southern India. BMC Health Serv Res. 2019;19:1004.

22. Garg S, Bebarta KK, Tripathi N. Performance of India's national publicly funded health insurance scheme, Pradhan Mantri Jan Arogaya Yojana (PMJAY), in improving access and financial protection for hospital care: findings from household surveys in Chhattisgarh state. BMC Public Health. 2020;20:949.

23. Mohanty SK, Kastor A. Out-of-pocket expenditure and catastrophic health spending on maternal care in public and private health centres in India: a comparative study of pre and post national health mission period. 2017. Health Economics Review. 2017. 7:31.

24. Government of India. NSS 60th Round. Jan - June 2004. Morbidity, Health Care and the Condition of the Aged. Ministry of Statistics and Programme Implementation. National Sample Survey Organization. http://mospi.nic.in/sites/default/files/publication_reports/507_final.pdf. Accessed 1 Nov 2019.

25. Government of India. Health in India-NSS 71st Round (January to June 2014): Ministry of Statistics and Programme Implementation. New Delhi: National Sample Survey Organisation NSSO; 2016.

26. Government of India. INDIA - Survey on Health Care July - June 1995-96, NSS 52nd Round. Ministry of Statistics and Programme Implementation. National Sample Survey Office. 2019. Available at. http://mospi.gov.in/sites/default/files/publication_reports/nss_71st_ki_health_30june15.pdf. Accessed 1 Nov 2019.

27. Government of India. NSS 60th Round: Jan - June 2004. Ministry of Statistics and Programme Implementation. National Sample Survey Organization. Dataset. Available at: http://microdata.gov.in/nada43/index.php/catalog/105. Accessed 1 Nov 2019. 
28. Government of India. Social Consumption in India - Health. NSS 71st Round. Jan-Jun 2014. Ministry of Statistics and Programme Implementation. National Sample Survey Office. 2015. Available at: http://microdata.gov.in/nada43/index.php/catalog/135. Accessed 1 Nov 2019.

29. Government of India. 2019. Key Indicators of Social Consumption in India - Health. NSS 75th Round. July 2017 to June 2018. Ministry of Statistics and Programme Implementation. National Sample Survey Office. November, 2019. Available at:http://www.mospi.gov.in/sites/default/files/NSS75250H/KI_Health_75th_Final.pdf. Accessed 10th June, 2020.

30. Government of India. Unit Level Data: Social Consumption in India - Health. NSS 75th Round. July 2017-June 2018. Ministry of Statistics and Programme Implementation. National Sample Survey Office. 2019. Available at:http://www.mospi.gov.in/unit-level-data-report-nss-75th-round-july-2017june-2018-schedule-250social-consumption-health. Accessed 10th June, 2020.

31. Katyal A, Singh PB, Samarth A, Bergkvist S, Rao M. Using the Indian national sample survey data in public health research. Natl Med J India. 2013;26(5):291-4.

32. Muraleedharan VR, Vaidyanathan G, Sundararaman T, Dash U, Ranjan A, Rajesh M. Invest More in Public Healthcare Facilities What Do NSSO 71 st and 75th Rounds Say? Economic \& Political Weekly. 2020; SEPTEMBER 12, 2020; vol IV no 37.

33. Dash A, Mohanty SK. Do poor people in the poorer states pay more for healthcare in India? 2019. BMC Public Health. 2019;19:1020.

34. Kastor A, Mohanty SK. Disease-specific out-of-pocket and catastrophic health expenditure on hospitalization in India: do Indian households face distress health financing? PLoS One. 2018;13(5):e0196106. https://doi.org/10.1371/journal.pone.0196106.

35. Labour Bureau. Statistical Data for Labour - Index Numbers. Ministry of Labour, Government of India. 2018. http://www.labourbureaunew.gov.in/LBO_indtab_new_Dec_2018.pdf. Accessed 10 June 2020.

36. Wagstaff A, Doorslaer E. Catastrophe and impoverishment in paying for healthcare: with applications to Vietnam 1993-98. Health Econ. 2003;12:92134.

37. Acharya A, Vellakkal S, Taylor F, Masset E, Satija A, Burke M, et al. Impact of national health insurance for the poor and the informal sector in low-and middle-income countries: a systematic review. London: EPPI-Centre, Social Science Research Unit, Institute of Education, University of London; 2012.

38. Giedion U, Alfonso AE, Díaz Y. The Impact of Universal Coverage Schemes in the Developing World: A Review of the Existing Evidence. UNICO Studies Series 25. Washington DC: The World Bank; 2013.

39. Erlangga D, Ali S, Bloor K. The impact of public health insurance on healthcare utilization in Indonesia: evidence from panel data. International Journal of Public Health. 2019;64:603-13.

40. Ghosh S. Health sector reforms and changes in prevalence of untreated morbidity, choice of healthcare providers among the poor and rural population in Indi. Int J Health Policy Manag. 2014;2(3):125-30.

41. Prinja S, Kumar M, Pinto AD, Jan S, Kumar R. Equity in Hospital Services Utilisation in India. Economic \& Political Weekly. 2013; March 23, 2013 vol xlviil no 12.

42. Gita S, lyer A, George A. Structural Reforms and Health Equity: A Comparison of NSS Surveys, 1986-87 and 1995-96. Economic and Political Weekly. 2002; Vol. 37, No. 14 (Apr. 6-12, 2002), pp. 1342-1352.

43. Nandi S, Schneider H, Dixit P. Hospital utilization and out of pocket expenditure in public and private sectors under the universal government health insurance scheme in Chhattisgarh state, India: lessons for universal health coverage. PLoS One. 2017;12(11):e0187904.

44. Mulyanto J, Kringos DS, Kunst AE. Socioeconomic inequalities in healthcare utilisation in Indonesia: a comprehensive survey-based overview. BMJ Open. 2019;9:e026164.

45. O’Donnell O. Access to health care in developing countries: breaking down demand side barriers. Cad Saúde Pública. 2007;23(12):2820-34.

46. Tripathy JP, Prasad BM, Shewade HD, Kumar AMV, Zachariah R, Chadha S, et al. Tropical Med Int Health. 2016. https://doi.org/10.1111/tmi.12732.

47. Rahman MM, Zhang C, Swe KT, Rahman MS, Islam MR, Kamrujjaman M, et al. Disease-specific out-of-pocket healthcare expenditure in urban Bangladesh: A Bayesian analysis. 2020. PLoS ONE 15(1): e0227565.

48. Murphy A, Palafox B, Walli-Attaei M, et al. The household economic burden of non-communicable diseases in 18 countries. BMJ Global Health. 2020;5:e002040.

49. Saksena P, Xu K, Elovainio R, Perrot J. Health services utilization and out-of-pocket expenditure at public and private facilities in low-income countries. World Health Report 2010 - Background Paper, No 20. World Health Organization, Geneva.

50. Kankeu HT, Saksena P, Xu K, Evans DB, et al. The financial burden from non-communicable diseases in low- and middle-income countries: a literature review. Health Research Policy Systems. 2013;11:31.

51. Samadi A, Rad EH. Determinants of Healthcare Expenditure in Economic Cooperation Organization (ECO) Countries: Evidence from Panel Cointegration Tests. International Journal of Health Policy Management. 2013;1(1):63-8.

52. Chowdhury S, Gupta I, Trivedi M, Prinja S. Inequity \& burden of out-of-pocket health spending: District level evidences from India. Indian J Med Res. 2018; 148, August 2018, pp 180-189 DOI: 10.4103/ijmr.IJMR_90_17.

53. Gupta I, Chowdhury S. Financing for Health Coverage in India: Issues and Concerns. IEG Working Paper No. 346. 2015. Institute of Economic Growth. Delhi 110007, India.

54. Garg CC, Karan AK. Reducing out-of-pocket expenditures to reduce poverty: a disaggregated analysis at rural-urban and state level in India. Health Policy Plann. 2009;24:116-28. doi:10.1093/heapol/czn046.

55. Karan A, Selvaraj S, Mahal A. Moving to Universal Coverage? Trends in the Burden of Out-Of-Pocket Payments for Health Care across Social Groups in India, 1999-2000 to 2011-12. PLoS ONE. 2014;9(8):e105162. doi:10.1371/journal.pone.0105162. 
56. Government of India. Situational Analyses- Backdrop to the NHP 2017. 2017. Ministry of Health and Family Welfare, Government of India.

57. Sundararaman T, Muraleedharan VR. Falling, Sick, Paying the Price. NSS 71st Round on Morbidity and Costs of Healthcare. Economic \& Political Weekly. 2015; AUGUST 15, 2015 vol I no 33.

58. Mishra S, Mohanty SK. Out-of-pocket expenditure and distress financing on institutional delivery in India. International Journal for Equity in Health. 2019;18:99. https://doi.org/10.1186/s12939-019-1001-7.

59. Datta BK, Husain MJ, Asma S. Assessing the relationship between out-of-pocket spending on blood pressure and diabetes medication and household catastrophic health expenditure: evidence from Pakistan. Int J Equity Health. 2019;18(1):9. doi:10.1186/s12939-018-0906-x. Jan 15.

60. Dalal K, Aremu O, Ussatayeva G, Biswas A. Out-of-pocket health expenditure and fairness in utilization of health care facilities in Cambodia in 2005 and 2010. F1000Research. 2017; 6:2066 https://doi.org/10.12688/f1000research.12801.1.

61. Beogo I, Huang N, Gagnon M, Amendah DD. Out-of-pocket expenditure and its determinants in the context of private healthcare sector expansion in subSaharan Africa urban cities: evidence from household survey in Ouagadougou. Burkina Faso J Prev Med Public Health. 2017;50(2):91-9.

62. Njagi P, Arsenijevic J, Groot W. Understanding variations in catastrophic health expenditure, its underlying determinants and impoverishment in SubSaharan African countries: a scoping review. Systematic Reviews. 2018;7:136. https://doi.org/10.1186/s13643-018-0799-1.

63. Okello NO, Njeru A. Factors Affecting Out-Of-Pocket Medical Expenditure Among Out Patients in Hospitals in Nairobi County. International Journal of Scientific and Research Publications. 2015; Volume 5, Issue 6, June 20151 ISSN 2250-3153.

64. Bhat R. Characteristics of Private Medical Practice in India: A Provider Perspective. Health Policy Plann. 1999;14(1):26-37.

65. Deolalikar AB, Jamison DT, Jha P, Laxminarayan R. Financing Health Improvements in India. 2008; Health Affairs, 27, no.4 (2008):978-990.

66. Dasgupta R, Nandi S, Kanungo K, Nundy M, Murugan G, Neog R. 2013. What the Good Doctor Said: A Critical Examination of Design Issues of the RSBY Through Provider Perspectives in Chhattisgarh, India. Social Change. 2013;43(2):227-243. doi:10.1177/0049085713493043.

67. Purohit BC. Private initiatives and policy options: recent health system experience in India. Health Policy Plan. 2001 Mar;16(1):87-97. doi:10.1093/heapol/16.1.87

68. Garg P, Nagpal J.. . Feb. A Review of Literature to Understand the Complexity of Equity, Ethics and Management for Achieving Public Health Goals in India. Journal of Clinical Diagnostic Research. 2014; Vol. -8(2):1-6.

69. Nandi S, Schneider H. When state-funded health insurance schemes fail to provide financial protection: an in-depth exploration of the experiences of patients from urban slums of Chhattisgarh, India. Glob Public Health. 2019. https://doi.org/10.1080/17441692.2019.1651369.

70. Rent P, Ghosh S. Understanding the Cash-Less Nature of Government-Sponsored Health Insurance Schemes: Evidence From Rajiv Gandhi Jeevandayee Aarogya Yojana in Mumbai. SAGE Open. 2015;5(4):1-10.

71. Devadasan N, Seshadri T, Trivedi M, Criel B. Promoting universal financial protection: evidence from the RashtriyaSwasthyaBimaYojana (RSBY) in Gujarat, India. Health Res Policy Syst. 2013;11(1):29. https://doi.org/10.1186/1478-4505-11-29.

72. Sengupta A, Mukhopadhyaya I, Weerasinghe MC, Karki A. The rise of private medicine in South Asia. BMJ. 2017;357:j1482.

73. Maurya D, Ramesh M. Program design, implementation and performance: the case of social health insurance in India. Health Econ Policy Law. 2019;14:487-508.

74. Hooda SK. Out-of-pocket Payments for Healthcare in India: Who Have Affected the Most and Why? Journal of Health Management. 2017;19(1):1-15. DOI:10.1177/0972063416682535.

75. Jana A, Basu R. Examining the changing health care seeking behavior in the era of health sector reforms in India: evidences from the National Sample Surveys 2004 \& 2014. Global Health Research and Policy. 2017; 2:6. DOI 10.1186/s41256-017-0026-y.

76. Brugha R, Pritze-Aliassime S. Promoting safe motherhood through the private sector in low- and middle-income countries. Bull World Health Organ. 2003;81:616-23.

77. Ferrinho P, Bugalho AM, Lerberghe WV. Is there a case for privatising reproductive health? Patchy evidence and much wishful thinking. In Studies in Health Services Organisation \& Policy, 17, 2001. Series editors: W. Van Lerberghe, G. Kegels, V. De Brouwere.

78. Amporfu E. Private hospital accreditation and inducement of care under the Ghanaian National Insurance Scheme. Health Economics Review. 2011;1:13.

79. Seyedin H, Afshari M, Isfahani P, Rakhshan A, Hasanzadeh E, Taherimirghaed M. Main Factors Leading to Supplier-Induced Demand in Iran: A Comprehensive Review. Health Scope. 2020; May; 9(2):e96366.

80. Sanders D, Nandi S, Labonte R, Vance C, Damme WV. From primary health care to universal health coverage-one step forward and two steps back. Lancet. 2019;394(10199):619-21. https://doi.org/10.1016/S0140-6736(19)31831-8.

81. Berman P, Rose L. The role of private providers in maternal and child health and family planning services in developing countries. HEALTH POLICY AND PLANNING. 1996;11(2):142-55.

82. Musgrove P Public and Private Roles in Health - Theory and Financing Patterns. World Bank Discussion Paper 339. 1996. World Bank. Washington DC.

83. World Bank. World development report: Making services work for poor people. Washington DC: World Bank and Oxford University Press; 2004.

84. World Bank. Public Ends Private Means, Strategic purchasing of Health Services. Washington DC: World Bank; 2007.

85. Gwatkin DR. For Whom to Buy? Are Free Government Health Services the Best Way to Reach the Poor? In: Preker AS, Langenbrunner JC, editors. Spending Wisely, Buying services for the Poor. Washington DC: World Bank; 2005.

86. Stallworthy G, Boahene K, Ohiri K, Pamba A, Knezovich J. Roundtable discussion: what is the future role of the private sector in health? Global Health. 2014;10:55.

87. Vining AR, Globerman S. Contracting-out health care services: a conceptual Framework. Health Policy. 1999;46:77-96. 
88. Le Grand J. Quasi-Market versus State Provision of Public Services: Some Ethical Considerations. Public Reason. 2011;3(2):80-9.

89. Donika D, Sealy S, Bergkvist S, Pernefeldt H. Innovative pro-poor healthcare financing and delivery models. Washington DC: Results for Development Institute; 2009.

90. HLSP Institute. The Private Sector as Health Provider. Available at: http://www.hlspinstitute.org/privatesectorinhealth/index.html.

91. Alvarez MH, Eslava-Castaneda C, Henao-Kaffure L, Orozco-Diaz J, Parra-Salas LE. Universal health coverage and capital accumulation: a relationship unveiled by the critical political economy approach. International Journal of Public Health. July 2020. Vol IV.

92. Mackintosh M, Channon A, Karan A, Selvaraj S, Zhao H, Cavagnero E, et al. What is the private sector? Understanding private provision in the health systems of low-income and middle-income. Lancet. 2016;6736(16):1-10.

93. Birn AE, Kumar R. 2018. Universal health coverage can best be achieved by public systems - The BMJ. thebmjopinion. https://blogs.bmj.com/bmj/2018/08/24/universal-health-coverage-public-systems/. Published 2018. Accessed September 6, 2020.

94. Kumar R. Public-private partnerships for universal health coverage? The future of "free health" in Sri Lanka. Globalization Health. 2019;15(Suppl 1):75. https://doi.org/10.1186/s12992-019-0522-6.

95. Stuckler D, Feigl A, Basu S, McKee M. The political economy of universal health coverage. Background paper for the global symposium on health systems research. Technical Report. 2010. WHO; Geneva.

96. Prince R. Universal health coverage in the global south: new models of healthcare and their implications for citizenship, solidarity and the public good. Tidsskriftet Michael. 2017;2:153-72.

97. Thresia CU. RISING PRIVATE SECTOR AND FALLING 'GOOD HEALTH AT LOW COST'.. HEALTH CHALLENGES IN CHINA, SRI LANKA, AND INDIAN STATE OF KERALA. International Journal of Health Services. 2013, Volume 43, Number 1, Pages 31-48.

98. Basu S, Andrews J, Kishore S, Panjabi R, Stuckler D. Comparative performance of private and public healthcare systems in low- and middle-income countries: a systematic review. PLoS Med. 2012;9(6):e1001244.

99. Hanson K, Gilson L, Goodman C, Mills A, Smith R, Feachem R, et al. Is private health care the answer to the health problems of the world's poor? PLoS Med 5(11): e233. doi:10.1371/journal.pmed.0050233.

100. Mills A, Brugha R, Hanson K, McPake B. What can be done about the private health sector in low income countries? Bull World Health Organ. 2002, 80 (4): http://dx.doi.org/10.1590/S0042-96862002000400012.

101. Tung E, Bennett S. Private sector, for-profi t health providers in low and middle income countries: can they reach the poor at scale? Global Health. 2014;10:52.

102. Bhattacharyya O, Khor S, McGahan A, Dunne D, Daar AS, Singer PA. Innovative health service delivery models in Low and Middle Income Contries - what can we learn from the private sector? Health Res Policy Systems. 2010;8:24-10.

103. Patouillard E, Goodman C, Hanson K, Mills A. Can working with the private for-profit sector improve utilization of quality health services by the poor? A systematic review of the literature. Int J Equity Health. 2007, 6 (17): doi:10.1186/1475-9276-6-17.

104. Montagu D, Goodman C. Prohibit, constrain, encourage, or purchase: how should we engage with the private health-care sector? Lancet. 2016; Aug 6;388(10044):613 - 21. doi: 10.1016/S0140-6736(16)30242-2.

105. Akin J, Birdsall N, de Ferranti D. Financing Health Services in Developing Coun tries. An Agenda for Reform. Washington DC: The World Bank; 1987.

106. Hooda SK. Health in the Era of Neoliberalism: Journey from State Provisioning to Financialisation. ISID Working Paper 196. December 2016. Institute for Studies in Industrial Development. New Delhi.

107. Shewade HD, Aggarwal AK. Health sector reforms: Concepts, market based reforms and health inequity in India. Educational Research. 2012; (ISSN: 2141-5161) Vol. 3(2) pp. 118-125 February 2012.

108. World Bank. India: New Directions in Health Sector Development at the State Level: An Operational Perspective. February 11, 1997. Population and Human Resources Division. Report No. 15753-IN. World Bank. Washington DC.

109. Hooda SK. Private Sector in Healthcare Delivery Market in India: Structure, Growth and Implications. ISID Working Paper 185.December 2015. Institute for Studies in Industrial Development. New Delhi.

110. World Bank. World Development Report 1993 - Investing in Health. New York: World Bank and Oxford University Press; 1993.

111. Selvaraju V. Health-care expenditure in rural India. Working Paper Series No. 90, National Council for Applied Economics Research (NCAER). 2003. New Delhi.

112. Selvaraj S, Karan AK. Deepening Health Insecurity in India: Evidence from National Sample Surveys since 1980s. Economic \& Political Weekly EPW october 3, 2009 vol xliv no 40.

113. Guruswamy M, Mazumdar S, Mazumdar P. Public Financing of Health Services in India: An Analysis of Central and State Government Expenditure. Journal of Health Management. 2008;10:1. 49-85.

114. Bonu S, Bhushan I, Peters DH. Incidence, Intensity, and Correlates of Catastrophic Out-of-Pocket Health Payments in India. ERD Working Paper No. 102. 2007. Asian Development Bank. Manila, Philippines.

115. Ghosh S. Catastrophic Payments and Impoverishment due to Out-of-Pocket Health Spending: The Effects of Recent Health Sector Reforms in India. Working Paper No.15. 2010. Asia Health Policy Program. India.

116. Prinja S, Aggarwal AK, et al. User Charges in Healthcare: Evidence of Effect on Service Utilisation and Equity from North India. Indian J Med Res. 2012;136(5):868-76. 
117. Chopra M, Sharkey A, Dalmiya N, Anthony D, Binkin N. Strategies to improve health coverage and narrow the equity gap in child survival, health, and nutrition. Lancet. 2012;380:1331-40.

118. Qin VM, Hone T, Millett C, et al. The impact of user charges on health outcomes in low-income and middle-income countries: a systematic review. BMJ Glob Health. 2019;3:e001087.

119. Shahrawat R, Rao KD. Insured yet vulnerable: out-of-pocket payments and India's poor. Health Policy Plann. 2012;27:213-21.

120. Virk AK, Atun R. Towards universal health coverage in India: a historical examination of the genesis of Rashtriya Swasthya Bima Yojana - The health insurance scheme for low-income groups. Public Health. 2015;129(6):810-7.

121. Malhotra S, Patnaik I, Roy S, Shah A. Fair Play in Indian Health Insurance. Working Paper No. 228; 2018. http://www.nipfp.org.in/publications/workingpapers/1822/. Accessed 14 Sept 2018.

122. Khetrapal S, Acharya A, Mills A. Assessment of the public-private-partnerships model of a national health insurance scheme in India. Social Science \& Medicine. 2019; 243 (2019) 112634.

123. Nandi S, Schneider H. Using an equity-based framework for evaluating publicly funded health insurance programmes as an instrument of UHC in Chhattisgarh State, India. Health Res Policy Sys. 2020;18:50. https://doi.org/10.1186/s12961-020-00555-3.

124. Lagomarsino G, Garabrant A, Adyas A, Muga E, Otoo N. Moving towards universal health coverage: health insurance reforms in nine developing countries in Africa and Asia. Lancet. 2012;380:933-43. https://doi.org/10.1016/S0140-6736(12)61147-7.

125. Erlangga D, Suhrcke M, Ali S, Bloor K. The impact of public health insurance on health care utilisation, financial protection and health status in low- and middle-income countries: A systematic review. 2019. PLoS ONE 14(8): e0219731. https://doi.org/10.1371/journal.pone.0219731.

126. Meng Q, et al. Trends in access to health services and financial protection in China between 2003 and 2011: a cross-sectional study. 2012. Lancet. Vol 379 March 3, 2012.

127. Nguyen H, Ivers R, Jan S, et al. Analysis of out of-pocket costs associated with hospitalized injuries in Vietnam. BMJ Glob Health. $2017 ; 2:$ e000082. https://doi.org/10.1136/bmjgh-2016-000082.

128. Mbau R, et al. A critical analysis of health care purchasing arrangements in Kenya: A case study of the county departments of health. 2018. Int $\mathrm{J}$ Health Plann Mgmt. 2018;1-19. https://doi.org/10.1002/hpm.2604.

129. Munge K, Mulupi S, Barasa EW, Chuma J. A critical analysis of purchasing arrangements in Kenya: the case of the National Hospital Insurance Fund. Int J Heal Policy Manag. 2018;7(3):244-54.

130. Bredenkamp C, Buisman LR. Financial protection from health spending in the Philippines: policies and progress. 2016. Health Policy and Planning, Volume 31, Issue 7, 1 September 2016, Pages 919-927,https://doi.org/10.1093/heapol/czw011.

131. Hanson K. 2016. Moving towards a purchasing model in low and middle income countries? Avaiable from: http://resyst.Ishtm.ac.uk @RESYSTresearch. Accessed 1 Nov 2019.

132. 132. Akhnif HE, Dkhimi F. 2017. Mixed provider payment system in Morocco: challenges of alignment. WHO. Geneva. Available at: https://www.who.int/health_financing/events/strategic-purchasing-meeting-2017-sessions/en/index1.html. Accessed September 5, 2019.

133. Mathauer I, Dkhimi F. Analytical guide to assess a mixed provider payment system. A guidance document, Department of Health Systems Governance and Financing. Geneva: World Health Organizaion; 2018.

134. Patel V, Parikh R, Nandraj S, Balasubramaniam P, Narayan K, Paul VK, et al. Assuring health coverage for all in India. Lancet. 2015;386:2422-35.

135. NITI Ayog. Health System for a New India: Building Blocks - Potential Pathways to Reform. November 2019. NITI Aayog (National Institute for Transforming India). New Delhi.

136. Chokshi M, Patil B, Khanna R, Neogi SB, Sharma J, Paul VK, et al. Health systems in India. J Perinatol. 2016;36:9-12.

137. Hooda SK. DETERMINANTS OF PUBLIC EXPENDITURE. ON HEALTH IN INDIA: The Panel Data Estimates. Institute for Studies in Industrial Development. ISID Working Paper 177. January 2015. New Delhi.

138. Gupta I, Ranjan A. Public expenditure on Non-Communicable Diseases \& Injuries in India: A budget-based analysis. PLoS ONE. 2019;14(9):e0222086. https://doi.org/10.1371/journal.pone.0222086.

139. Acharya D, Vaidyanathan G, Muraleedharan VR, Dheenadayalan DS, Dash U. Do the Poor Benefit from Public Spending on Healthcare in India? Results from Benefit (Utilisation) Incidence Analysis in Tamil Nadu and Orissa. India: Consortium for Research on Equitable Health Systems (CREHS). Chennai; 2011.

140. Bose M, Dutta A. Health financing strategies to reduce out of pocket burden in India: a comparative study of three states. BMC Health Services Research. 2018;18:830. https://doi.org/10.1186/s12913-018-3633-5.

141. Peters DH, Yazbeck AS, Sharma RR, Ramana GNV, Pritchett LH, Wagstaff A. Better health systems for India's poor: findings, analysis, and options. Washington DC: The World Bank; 2002.

142. Nandi S, Schneider H, Garg S. Assessing geographical inequity in availability of hospital services under the state-funded Universal Health Insurance Scheme in Chhattisgarh state, India, using a composite vulnerability index. Glob Health Action. 2018;11:1541220.

143. Gupta A, Mondal S. Health spending, macroeconomics and fiscal space in countries of the World Health Organization South-East Asia Region. WHO South-East Asia J Public Health. 2014;3(3-4):273-84.

144. Sundararaman T, Mukhopadhyay I, Muraleedharan VR. No Respite for Public Health. Economic \& Political Weekly. 2016; april 16, 2016 vol II no 16.

145. National Health Systems Resource Centre. 2018. Comprehensive Primary Health Care - Operational Guidelines. Available at: https://www.nhm.gov.in/New_Updates_2018/NHM_Components/Health_System_Stregthening/Comprehensive_primary_health_care/letter/Operational_GI 
Accessed on: 10th June, 2020.

146. Gerdtham U, Jonsson B, MacFarlan M, Oxley H. THE DETERMINANTS OF HEALTH EXPENDITURE IN THE OECD COUNTRIES: A POOLED DATA ANALYSIS in Zweifel P, editor, Health, the Medical Profession, and Regulation. 1998.

147. Raeesi P, Harati-Khalilabad T, Rezapour A, Azari S, Javan-Noughabi J. Effects of private and public health expenditure on health outcomes among countries with different health care systems: 2000 and 2014. Med J Islam Repub Iran. 2018 (1 May);32.35. https://doi.org/10.1419 6/mjiri.32.35.

148. Petrera Pavone M, Jiménez Sánchez E. Determinantes del gasto de bolsillo en salud de la población pobre atendida en servicios de salud púbicos en Perú, 2010-2014. Rev Panam Salud Publica. 2018;42:e20. https://doi.org/10.26633/RPSP.2018.20.

149. Asante A, Price J, Hayen A, Jan S, Wiseman V. Equity in Health Care Financing in Low- and Middle-Income Countries: A Systematic Review of Evidence from Studies Using Benefit and Financing Incidence Analyses. PLoS ONE. 2016;11(4):e0152866. doi:10.1371/journal.pone.0152866.

150. Rannan-Eliya R, Sikurajapathy L, Sri Lanka. "Good Practice" in Expanding Health Care Coverage. Research Studies Series 3. Washington DC: Institute for Health Policy, The World Bank; 2009.

151. Balabanova D, McKee M, Mills A, editors. 'Good health at low cost' 25 years on. What makes a successful health system? London: London School of Hygiene \& Tropical Medicine; 2011.

152. Tangcharoensathien V, Mills A, Palu T. Accelerating health equity: the key role of universal health coverage in the Sustainable Development Goals. BMC Med. 2015;13:101. DOI 10.1186/s12916-015-0342-3.

\section{Supplementary Files}

This is a list of supplementary files associated with this preprint. Click to download.

- AdditionalFileS1StudyVariables.docx

- AdditionalFileS1StudyVariables.docx

- AdditionalFileS2SampleProfile.docx

- AdditionalFiles2SampleProfile.docx

- AdditionalFileS3LogisticRegressionforUtilisation.docx

- AdditionalFileS3LogisticRegressionforUtilisation.docx

- AdditionalFileS4LinearRegressionforOOPE.docx

- AdditionalFileS4LinearRegressionforOOPE.docx

- AdditionalFileS5LogisticRegressionforCHE25.docx

- AdditionalFileS5LogisticRegressionforCHE25.docx

- AdditionalFileS6DID.docx

- AdditionalFileS6DID.docx

- AdditionalFileS7RegressionforPublicUtilisation.docx

- AdditionalFileS7RegressionforPublicUtilisation.docx 